\title{
The role of nitric oxide synthase isoforms and arginase in the pathogenesis of diabetic foot ulcers: possible modulatory effects by transforming growth factor beta 1
}

\author{
E.B. Jude ${ }^{1}$, A.J.M Boulton ${ }^{1}$, M.W.J. Ferguson ${ }^{2}$, I. Appleton ${ }^{2}$ \\ ${ }^{1}$ The Department of Medicine/Diabetes, Manchester Royal Infirmary, Manchester, UK \\ ${ }^{2}$ The School of Biological Sciences, The University of Manchester, Manchester, UK
}

\begin{abstract}
Aims/hypothesis. L-arginine, an amino acid involved in wound healing, is metabolised by one of two pathways; nitric oxide synthase and arginase. If metabolised by nitric oxide synthase, this can result in tissue destruction, or matrix deposition if metabolised by arginase. The aim therefore was to investigate the role of these enzymes in the pathogenesis of diabetic foot ulcers.

Methods. The activity, proteins by Western blot analysis and cellular distribution (using immunocytochemistry) of these enzymes were measured in diabetic foot ulcers, diabetic skin and normal skin.

Results. Total and inducible nitric oxide synthase $(p<0.001)$ and endothelial nitric oxide synthase were increased in diabetic ulcers compared with diabetic and normal skin and were associated with increased plasma nitrite concentrations in diabetic ulcers $(p<0.05)$. Inducible nitric oxide synthase was the major isoform, with the macrophage being the
\end{abstract}

predominant cellular source. Similarly arginase activity was increased $(p<0.01)$ in diabetic ulcers. The protein levels corroborated with the activity data, with the fibroblast being the major cellular source. The spatial and cellular distribution of the two enzyme systems was distinct. Transforming growth factor-beta1 was decreased in diabetic ulcers in comparison with diabetic skin and normal skin.

Conclusion/interpretation. Increased nitric oxide synthase activity in diabetic foot ulcers may be responsible for the impaired healing in this disease. Furthermore, the increased activity of arginase could account for the characteristic callus formation around these ulcers. In addition, the lower concentrations of transforming growth factor-beta1 in diabetic ulcers may explain the raised concentrations of nitric oxide in this condition. [Diabetologia (1999) 42: 748-757]

Keywords Nitric oxide, NOS, arginase, foot ulcers, diabetic neuropathy.

patient. It is the commonest cause of admission to hospital amongst diabetic patients [2] resulting in $50-70 \%$ of all non-traumatic amputations [3] with a cost of at least $£ 7000$ per case in the United Kingdom [4]. Furthermore, with an increasingly aged population there is likely to be a rise in the incidence of these ulcers. It has therefore been the goal of clinicians for years to stimulate the normal reparative process in this debilitating disorder.

The severe tissue destruction associated with DFUs suggests a number of candidate factors in their aetiology, in particular the metabolism of $\mathrm{L}$-arginine is vital in the repair process. The metabolism of $\mathrm{L}$ -

arginine by the enzyme nitric oxide synthase (NOS)
Corresponding author: E.B. Jude, MRCP, M7 Records, Department of Medicine/Diabetes, Manchester Royal Infirmary, Oxford Road, Manchester, M13 9WL, UK

Abbreviations: NO, Nitric oxide; NOS, nitric oxide synthase; $i \mathrm{NOS}$, inducible nitric oxide synthase; ecNOS, endothelial nitric oxide synthase; DFU, diabetic foot ulcer. 
results in the formation of nitric oxide (NO) and Lcitrulline. Nitric oxide is a free radical involved in extracellular and intracellular neurotransmission, cell mediated cytotoxicity and endothelium-dependent relaxation of vascular smooth muscle. A number of cell types are capable of generating $\mathrm{NO}$ via cell specific NOS isoforms [5]. A constitutive, calcium-dependent isoform of NOS is present in endothelial cells (ecNOS) and neurones. A second, calcium-independent isoform of NOS can be induced in macrophages, vascular smooth muscle and polymorphonuclear neutrophils [5]. The production of NO by macrophages accounts for their anti-microbial and antitumour activity and is the first line in host defence of intracellular microbial killing [6-9]. L-arginine is the only amino acid required for this function [10-12]. Under low L-arginine concentrations, in addition to NO, NOS can generate other oxygen free radicals such as superoxide [11-13]. Such conditions may arise in a healing wound, where L-arginine is the only amino acid which decreases with time [14]. Furthermore, $\mathrm{NO}$ and superoxide can spontaneously combine to form the potent oxidants peroxynitrite and peroxynitrous acid which decompose to form $\mathrm{OH}$ and $\mathrm{NO}_{2}$, the decomposition products being more toxic than NO itself $[15,16]$. Thus the effects of NO and other free radicals either alone or in combination can result in severe matrix destruction.

In addition to the NOS pathway, L-arginine can be metabolised via the arginase pathway to ornithine and urea. Ornithine can subsequently be converted to proline, the building block for collagen synthesis. Ornithine can also be converted to the polyamines, putrescine, spermidine and spermine, which are essential for cell growth and differentiation [17]. The modulation of L-arginine metabolism is thus central to the normal course of wound repair, abnormalities of which are possibly involved in the pathophysiology of DFUs. The aim of this study was to test the hypothesis that abnormalities of L-arginine metabolism may be involved in the pathogenesis of DFUs, by determining the activity, proteins and cellular distribution of NOS and arginase in DFUs comparing diabetic patients and control subjects. An insight into the underlying mechanisms in the pathogenesis of DFUs may ultimately lead to better therapies or the prevention of foot ulcers or both.

\section{Subjects and methods}

Patients. Subjects studied were 14 controls, 22 diabetic patients and 22 DFU patients. All three groups were matched for age and sex and diabetic groups were matched for type, duration and treatment of diabetes. Neuropathy was defined as vibration perception threshold (VPT) more than $25 \mathrm{~V}$ and peripheral vascular disease was diagnosed on the basis of ankle brachial pressure index (ABPI) (normal >0.9). The majority of ulcers $(n=20)$ were of neuropathic aetiology $(\mathrm{VPT}>25 \mathrm{~V})$ and two
Table 1. Characteristics of study subjects

\begin{tabular}{llll}
\hline & Control & Diabetic & DFU \\
\hline Number & 14 & 22 & 22 \\
Males/Females & $7 / 7$ & $11 / 11$ & $11 / 11$ \\
Age (years) & $52.1 \pm 1.2$ & $49.9 \pm 1.7$ & $52.7 \pm 1.3$ \\
Duration (years) & & $18.2 \pm 2.3$ & $17.8 \pm 2.7$ \\
Type I/II diabetes & & $11 / 11$ & $11 / 11$ \\
Treatment: Insulin & & 14 & 15 \\
& 8 & 7 \\
HbA Ic $_{\text {OHA }}$ & & $8.4 \pm 0.4$ & $9.22 \pm 0.4$ \\
Neuropathy & & 20 & 20 \\
Neuroischaemia & & 2 & 2 \\
\hline
\end{tabular}

OHA, oral hypoglycaemic agents

ulcers were of neuroischaemic aetiology (VPT $>25 \mathrm{~V}$ and ABPI $<0.9)$. Patients with severe ischaemia $(\mathrm{ABPI}<0.5)$ were not included in the study. Patients with evidence of diabetic nephropathy (serum creatinine $>150 \mu \mathrm{mol} / \mathrm{l}$ ), severe uncontrolled hypertension, ischaemic heart disease and clinical evidence of infection were excluded. The presence of infection in DFUs was ruled out clinically on the basis of evidence of inflammation, cellulitis or discharge from the ulcer. No subjects were on non-steroidal anti-inflammatory drugs, hormone replacement therapy, nitrates or antibiotics at the time of sampling (Table 1$)$. Skin biopsies $\left(0.75 \mathrm{~cm}^{2}\right)$ were taken from the dorsum of the foot or the leg of non-diabetic subjects and diabetic patients and from the edge of the ulcer of DFU patients ( $n=11$ per group). Diabetic foot ulcer biopsies were taken from plantar ulcers in four patients, four from dorsal and three from lateral foot ulcers. The tissue was bisected and one half placed immediately in liquid $\mathrm{N}_{2}$ for biochemical analysis. The remaining tissue, for histological and immunohistological observations, was snap frozen in $\mathrm{n}$-Hexane in a bath of liquid $\mathrm{N}_{2}$ and stored under liquid $\mathrm{N}_{2}$ till use. This study was approved by the local ethics committee and patients had to give written consent for undergoing a biopsy.

Measurement of plasma nitrite concentrations. Blood $(6 \mathrm{ml})$ was taken from the antecubital vein and collected in heparin/ lithium tubes. Plasma was prepared by centrifuging samples at $4000 \times g$ for $10 \mathrm{~min}$. The plasma was then decanted and frozen in liquid $\mathrm{N}_{2}$ till use. Nitrite was measured using the Griess reaction. Briefly $100 \mu \mathrm{l}$ of standard (0-100 $\mu \mathrm{mol} / \mathrm{l} \mathrm{Na}$ nitrite) or sample were added to $100 \mu \mathrm{l}$ of reagent which consisted of equal volumes of $10 \mathrm{~g} / \mathrm{l}$ sulphanilamide (in $0.5 \% \mathrm{H}_{3} \mathrm{PO}_{4}$ ) and $1 \mathrm{~g} / \mathrm{l}$ of Naphthylethylenediamine all prepared using HPLC grade water. Nitrite formation was then assessed spectrophotometrically at a wavelength of $570 \mathrm{~nm}$.

Assessment of nitric oxide synthase activity. Biopsy samples were homogenised, on ice, in TRIS buffer ( $50 \mathrm{mmol} / \mathrm{l}, \mathrm{pH} 7.4)$ containing phenylmethylsulphonyl fluoride $(1 \mathrm{mmol} / \mathrm{l})$, pepstatin A $(1.5 \mathrm{mmol} / \mathrm{l})$ and leupeptin $(0.2 \mu \mathrm{mol} / \mathrm{l})$. Activity of NOS was measured as the ability of tissue homogenates to convert $\left[{ }^{3} \mathrm{H}\right]$ L-arginine to $\left[{ }^{3} \mathrm{H}\right]$ L-citrulline. Samples $(n=11$ per group) were incubated at room temperature for $30 \mathrm{~min}$ in the presence of NADPH (1 mmol/l), calmodulin (30 nmol/l), L-valine $(50 \mathrm{mmol} / \mathrm{l}$; to inhibit arginase activity), tetrahydrobiopterin (5 $\mu \mathrm{mol} / \mathrm{l}$; Alexis Corporation, San Diego, Calif., USA), calcium $(2 \mathrm{mmol} / \mathrm{l})$ and a mixture of unlabelled and $\left[{ }^{3} \mathrm{H}\right] \mathrm{L}$ arginine $(10 \mathrm{mmol} / \mathrm{l}$; Amersham International, Amersham, $\mathrm{UK}$ ). In experiments to assess the contribution of $i$ NOS (calci- 
um-independent) to total NOS activity, calcium was replaced with EGTA $(1 \mathrm{mmol} / \mathrm{l})$. In addition, L-citrulline formation was determined in the absence of NADPH as a measure of non-specific conversion of L-arginine. Incubations were terminated by the addition of $1 \mathrm{ml}$ HEPES ( $20 \mathrm{mmol} / \mathrm{l}, \mathrm{pH} 5.5)$ containing EGTA $(1 \mathrm{mmol} / \mathrm{l})$ and EDTA $(1 \mathrm{mmol} / \mathrm{l})$. The newly formed $\left[{ }^{3} \mathrm{H}\right] \mathrm{L}$-citrulline was separated from the $\left[{ }^{3} \mathrm{H}\right] \mathrm{L}$-arginine by passing the reaction mixture over Dowex columns $(1 \mathrm{ml}$; Sigma, Poole, UK) and the eluted labelled material was measured using a liquid scintillation counter. Results are expressed as pmol L-citrulline/mg protein. The protein concentration in the homogenates was measured by the Bradford assay [18], using bovine serum albumin as a standard.

Assessment of arginase activity. This was determined according to a method reported previously [19]. We added $10 \mathrm{mmol} / \mathrm{l}$ $\mathrm{MnCl}_{2}$ in $50 \mathrm{mmol} / \mathrm{l}$ TRIS $\mathrm{HCl}(\mathrm{pH} 7.5)$ to each sample and the enzyme was activated by heating at $55^{\circ} \mathrm{C}$ for $10 \mathrm{~min}$. Then $0.5 \mathrm{~mol} / \mathrm{l} \mathrm{L}$-arginine was added and incubated at $37^{\circ} \mathrm{C}$ for $1 \mathrm{~h}$ and the reaction stopped by the addition of $\mathrm{H}_{2} \mathrm{SO}_{4}(18.4 \mathrm{~mol} /$ 1), $\mathrm{H}_{3} \mathrm{PO}_{4}(14.7 \mathrm{~mol} / \mathrm{l})$ and $\mathrm{H}_{2} \mathrm{O}(1: 3: 7)$. The urea formed was then assessed spectrophotometrically $(540 \mathrm{~nm})$ after the addition of 9\% 1-phenyl-1,2-propanedione-2-oxime (in ethanol) and heating at $100^{\circ} \mathrm{C}$ for $45 \mathrm{~min}$. Results are expressed as $\mu \mathrm{g}$ urea/mg protein.

Immunolocalization of nitric oxide synthase isoforms, arginase and TGF- $\beta 1$. Cryostat sections ( $8 \mu \mathrm{m} ; n=11$ per group) were thaw mounted on poly-L-lysine coated slides, air dried and stored at $-20^{\circ} \mathrm{C}$ till use. Prior to immunolabelling, sections were fixed in acetone for $10 \mathrm{~min}$. Endogenous peroxidases were quenched with $0.3 \% \mathrm{H}_{2} \mathrm{O}_{2}$ in methanol and sections washed in phosphate buffered saline (PBS). Non specific binding of IgGs was blocked using normal goat serum $1: 50$ in $0.1 \%$ bovine serum albumin (essentially globulin free) in PBS. The sections were incubated with primary antibody at $4^{\circ} \mathrm{C}$ overnight (all 1:500, except TGF- $\beta 1$ which was used at 1:20), washed and incubated for a further $30 \mathrm{~min}$ with a biotinylated secondary antibody. Following a further $30 \mathrm{~min}$ incubation with ABC horseradish-peroxidase (Vectastain, Vector Laboratories, Peterborough, UK) the substrate $(0.05 \% 3.3$-diaminobenzidine tetra hydrochloride in $50 \mathrm{mmol} / \mathrm{l}$ TRIS buffer, pH 7.4; Sigma, Poole, UK) was added for the appropriate time period $(5-10 \mathrm{~min})$. This resulted in positive cells labelling brown. Primary antiserum was replaced with normal serum of the host species of the secondary antibody, as a negative control. Morphological observations were confirmed using routine histological stains, haematoxylin and eosin, and toluidine blue.

Western blot analysis of nitric oxide synthase isoforms, arginase and $T G F-\beta 1$. Tissue homogenates were boiled (10 min) with gel loading buffer (TRIS, $50 \mathrm{mmol} / \mathrm{l}$, pH 7.4; SDS, $10 \%$; glycerol, $10 \%$; 2-mercaptoethanol, $10 \%$; bromophenol blue, $2 \mathrm{mg} / \mathrm{ml}$ ) in a ratio of $1: 1$ and centrifuged at $10000 \times g$, for $10 \mathrm{~min}$. Protein concentrations of the supernatants were measured as above, and total protein-equivalents for each sample separated on $10 \%$ SDS-polyacrylamide mini-gels, and in the case of TGF- $\beta 1,15 \%$ gel (Hoefer; Staffordshire, UK) using the Laemmli buffer system and transferred to $0.45 \mu \mathrm{m}$ nitrocellulose membranes and in the case of TGF- $\beta 1$ a $0.22 \mu \mathrm{m}$ membrane. Non-specific IgGs were blocked with $3 \%$ dried milk protein and incubated with primary antibody (all 1:1000) overnight at $4{ }^{\circ} \mathrm{C}$. Bands were detected using an amplified alkaline phosphatase kit and developed with 5-bromo-4-chloro-3-indolylphosphate/nitroblue tetrazolium (Sigma, Poole, UK) as a chromogen. Broad range prestained rainbow markers (Biorad
Laboratories, Hemel Hempstead, UK) were used for molecular weight determinations.

Antibodies. Polyclonal rabbit anti-human endothelial cell NOS (Affiniti, Mamhead, Exeter, UK); polyclonal rabbit anti-human $i$ NOS (gift Dr. C. Bryant, Cambridge University, UK); polyclonal rabbit anti-bovine arginase (Biogenesis, Poole, UK); Polyclonal rabbit anti-human TGF- $\beta 1$ (Santa Cruz, Biotechnology Autogen Bioclear, Calne, UK). All secondary biotinylated antibodies and conjugates were obtained from Vector Laboratories, Peterborough, UK and the amplified alkaline phosphatase kit for western blot analysis from Sigma, Poole, UK.

Data analysis. The Statistics Package for Social Sciences was used for all data analysis (SPSS, Chicago, Ill., USA). Results are expressed as the means \pm SEM. For non-parametrically distributed data the Mann Whitney U-test was used, with a $p$ value of less than 0.05 being considered as statistically significant.

\section{Results}

Plasma nitrite concentrations. The results showed a decrease $(p<0.001)$ in plasma nitrite concentrations in diabetic patients $(4.53 \pm 0.8 \mu \mathrm{mol} / 1$ nitrite $/ \mathrm{mg}$ protein) compared with control subjects (11.3 \pm $1.9 \mu \mathrm{mol} / \mathrm{l}$ nitrite $/ \mathrm{mg}$ protein) By contrast, DFU patients had raised $(p<0.05)$ plasma nitrite concentrations compared with diabetic patients (12.2 \pm $2.0 \mu \mathrm{mol} / \mathrm{l}$ nitrite/mg protein; Fig. $1 \mathrm{a}$ ). The type of diabetes had no significant effect on nitrite concentrations in either the DFU patients or the diabetic patients $(10.8 \pm 1.2 \mu \mathrm{mol} / \mathrm{l}$ and $14.2 \pm 3.5 \mu \mathrm{mol} / \mathrm{l} \mathrm{ni}-$ trite/mg protein, DFU patients with Type I (insulindependent) and Type II (non-insulin-dependent) diabetes mellitus respectively, $p=0.6$; and $3.04 \pm$ $0.7 \mu \mathrm{mol} / \mathrm{l}$ and $6.6 \pm 1.4 \mu \mathrm{mol} / \mathrm{l}$ nitrite $/ \mathrm{mg}$ protein, Type I and Type II diabetic patients respectively, $p=0.06$ ). In addition, diabetes treatment (insulin or oral hypoglycaemic agents) had no apparent effect on nitrite concentrations in the DFU patients $(10.4 \pm 1.1 \mu \mathrm{mol} / \mathrm{l}$ and $15.9 \pm 5.1 \mu \mathrm{mol} / \mathrm{l}$ nitrite $/ \mathrm{mg}$ protein respectively, $p=0.48$ ). In the non-ulcer diabetic patients, insulin treatment was, however, associated with a reduction in nitrite $(3.28 \pm 0.7 \mu \mathrm{mol} / \mathrm{l}$ nitrite/mg protein) compared with oral hypoglycaemic treatment $(8.03 \pm 1.8 \mu \mathrm{mol} / \mathrm{l}$ nitrite $/ \mathrm{mg}$ protein, $p<0.05)$. No correlation between nitrite concentrations and $\mathrm{HbA}_{1 \mathrm{c}}$ was observed in either the DFU group or diabetic patients in relation to the concentrations of nitrite.

Nitric oxide synthase activity. The results showed increased $(p<0.001)$ total NOS activity in DFUs $(251.5 \pm 62 \mathrm{pmol}$ L-citrulline $/ \mathrm{mg}$ protein) compared with diabetic skin $(132.5 \pm 31 \mathrm{pmol} \mathrm{L}$-citrulline $/ \mathrm{mg}$ protein) and normal skin (172 \pm 76 pmol L-citrulline/ mg protein). In all groups $i$ NOS activity accounted 

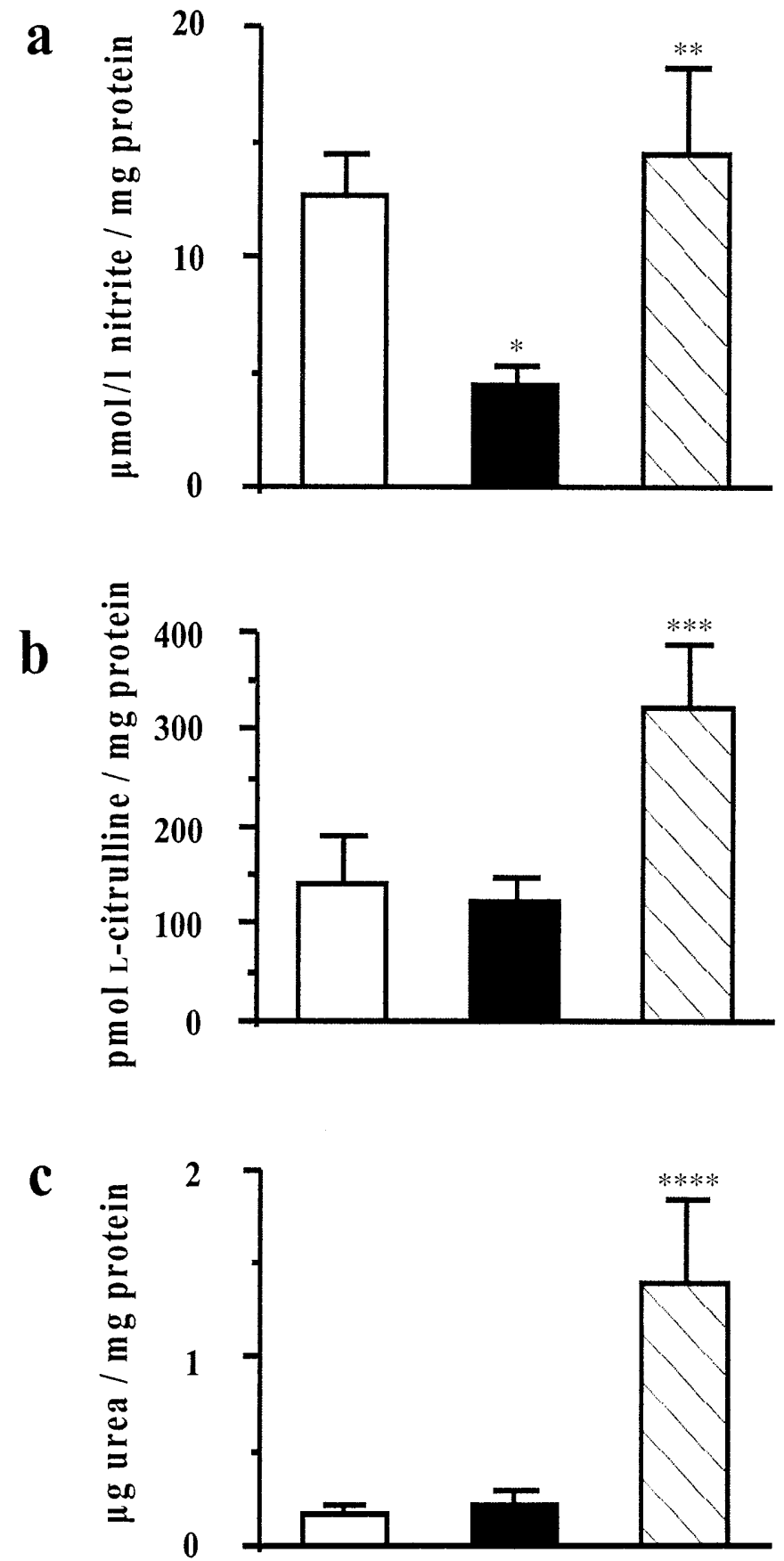

Fig. 1a-c The a) plasma nitrite concentrations, b) $i$ NOS activity and c) arginase activity in normal skin (open bars), diabetic skin (closed bars) and DFU biopsies (hatched bars) are shown. Each point represents the means \pm SEM. $* p<0.001$ vs normal skin; $* * p<0.05$ vs diabetic skin; $* * * p<0.001$ vs diabetic and normal skin; $* * * * p<0.01$ vs diabetic and normal skin

for virtually all NOS activity (normal skin, $143 \pm 48$; diabetic skin, $123 \pm 23$; DFU, $323 \pm 66$ pmol L-citrulline/mg protein) (Fig. 1b).

Arginase activity. Arginase activity was increased $(p<0.01)$ in DFUs $(1.4 \pm 0.45 \mu \mathrm{g}$ urea/mg protein $)$ compared with diabetic skin $(0.22 \pm 0.07 \mu \mathrm{g}$ urea/mg protein $)$ and normal skin $(0.16 \pm 0.05 \mu \mathrm{g}$ urea/mg protein) (Fig. 1c).

Immunolocalization of ecNOS. In normal skin, ecNOS was localised to endothelial cells of all vessels (Fig.2). In diabetic skin the labelling was reduced (Fig. 2b). By contrast, the degree of ecNOS immunoreactivity was increased in DFUs. This profile was, however, spatially related. In DFU patients the skin juxtaposed to the ulcer contained reduced labelling in comparison to control skin. The edge and base of the ulcer contained, however, numerous ecNOS positive capillaries, the number decreasing the more distal from the edge of the ulcer (Fig. 2c)

Immunolocalization of $i N O S$. In normal skin and diabetic skin, $i$ NOS immunoreactivity was restricted to the smooth muscle of a number of blood vessels (Fig. 3 a,b). In addition, the smooth muscle cells of the erector pili muscles were also labelled. In DFU patients (Fig. $3 \mathrm{c}$ ) high $i$ NOS immunoreactivity was observed at the margins of the ulcer, predominantly localised to the vascular smooth muscle. In the ulcer region large numbers of inflammatory cells, mainly macrophages, were also observed to be immunopositive for $i$ NOS.

Immunolocalization of arginase. In normal skin, arginase immunolabelling was localised to endothelial cells and the smooth muscle of the erector pili muscles (Fig. 4). A small proportion of fibroblasts within the dermis also showed arginase immunoreactivity. In diabetic skin, the labelling of arginase was greatly and consistently reduced, being restricted to a small number of blood vessels in the dermis (Fig. 4b). In DFU samples arginase immunoreactivity was considerably raised. Numerous fibroblasts at the edge of the ulcer and in the dermis adjacent to the ulcer margin showed intense labelling for arginase. Immunoreactivity decreased towards the central regions of the ulcer. Endothelial cells of a number of blood vessels both within the ulcer lesion and in the dermis adjacent to the ulcer also labelled positively for arginase.

Immunolocalization of TGF- $\beta 1$. In normal and diabetic skin intense immunoreactivity of TGF- $\beta 1$ was observed in all layers of the epidermis with the basal layer expressing the most (Fig. 5). In diabetic skin, labelling associated with matrix components was also discerned (Fig. 5b). A similar profile was seen in normal skin, however, the intensity of immunoreactivity was greater compared with diabetic skin (Fig. $5 \mathrm{a}$ ). Immunoreactivity of TGF- $\beta 1$ associated with vascular endothelial cells of capillaries and larger blood vessels was observed in both normal (Fig. 5 d) and diabetic skin. In DFUs the intensity of TGF- $\beta 1$ immunoreactivity was considerably less and in some instances none could be seen (Fig. 5c). Immunolabel- 

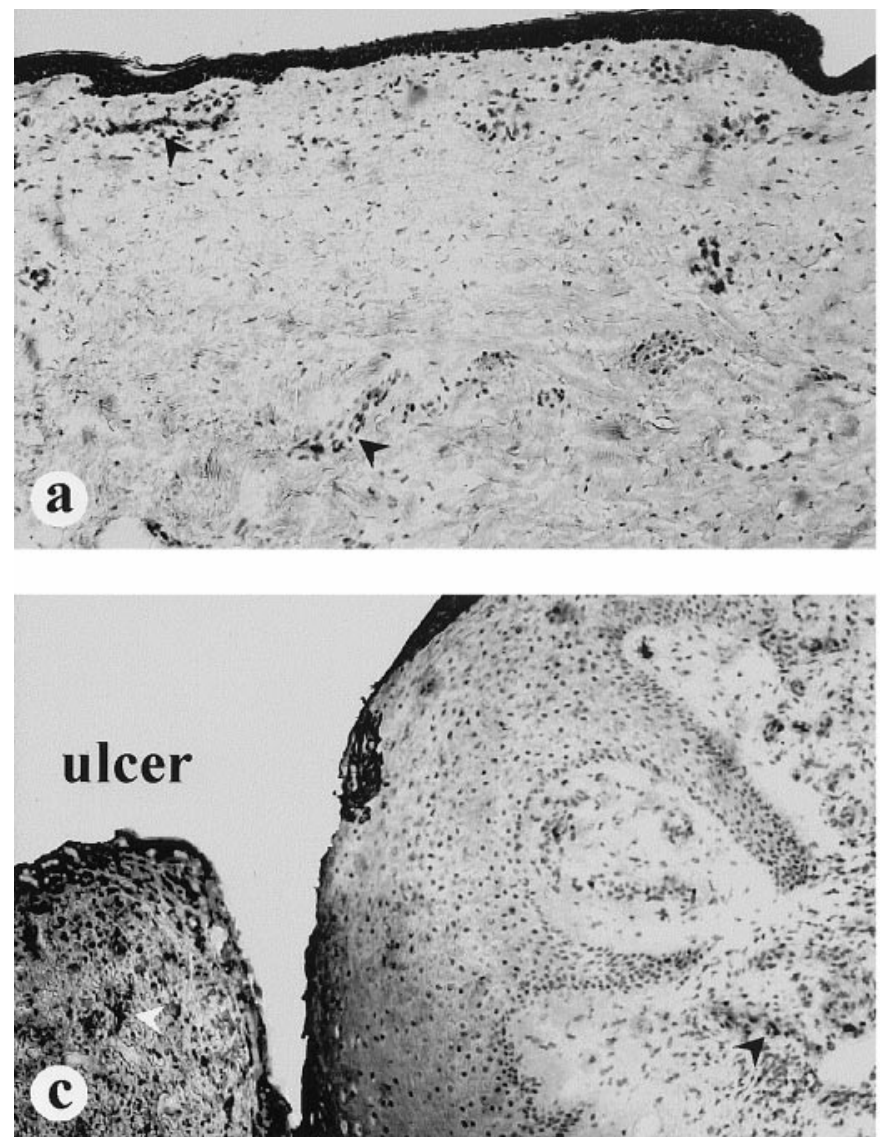

Fig. 2a-d The immunolocalization of ecNOS in a) normal skin; b) diabetic skin and c) DFU biopsies is shown. In a and $\mathbf{b}$, immunoreactivity is localised to endothelial cells lining the capillaries in the dermis (arrows). In c, numerous ecNOS positive blood vessels at the margins of the ulcer (arrows) are illustrated and $\mathbf{d}$ serial section of $\mathbf{c}$, as a negative control. Magnification $\times 65$

ling of a proportion of cells in the basal layer of the epidermis juxtaposed to the ulcer could, however, be identified, the granulosum and spinosum were negative. Immunoreactivity of TGF- $\beta 1$ was absent in the dermis, blood vessels in the ulcer and in the dermis adjacent to the ulcer were also unlabelled. Macrophages although present in the ulcer showed no immunoreactivity to TGF- $\beta 1$ (Fig. 5 e).

Western blot analysis of ecNOS. At a band of approximately $140 \mathrm{kDa}$, ecNOS protein occurred as determined with human endothelial cell NOS protein as a standard (data not shown). Diabetic skin had the lowest levels of $e c$ NOS protein, normal skin had more and DFU still more (Fig. 6a).

Western blot analysis of iNOS. The profile of iNOS protein in normal skin, diabetic skin and DFU patients is illustrated in Fig. 6b. Protein levels occurred at a band of $140 \mathrm{KDa}$ as determined using lipopo-
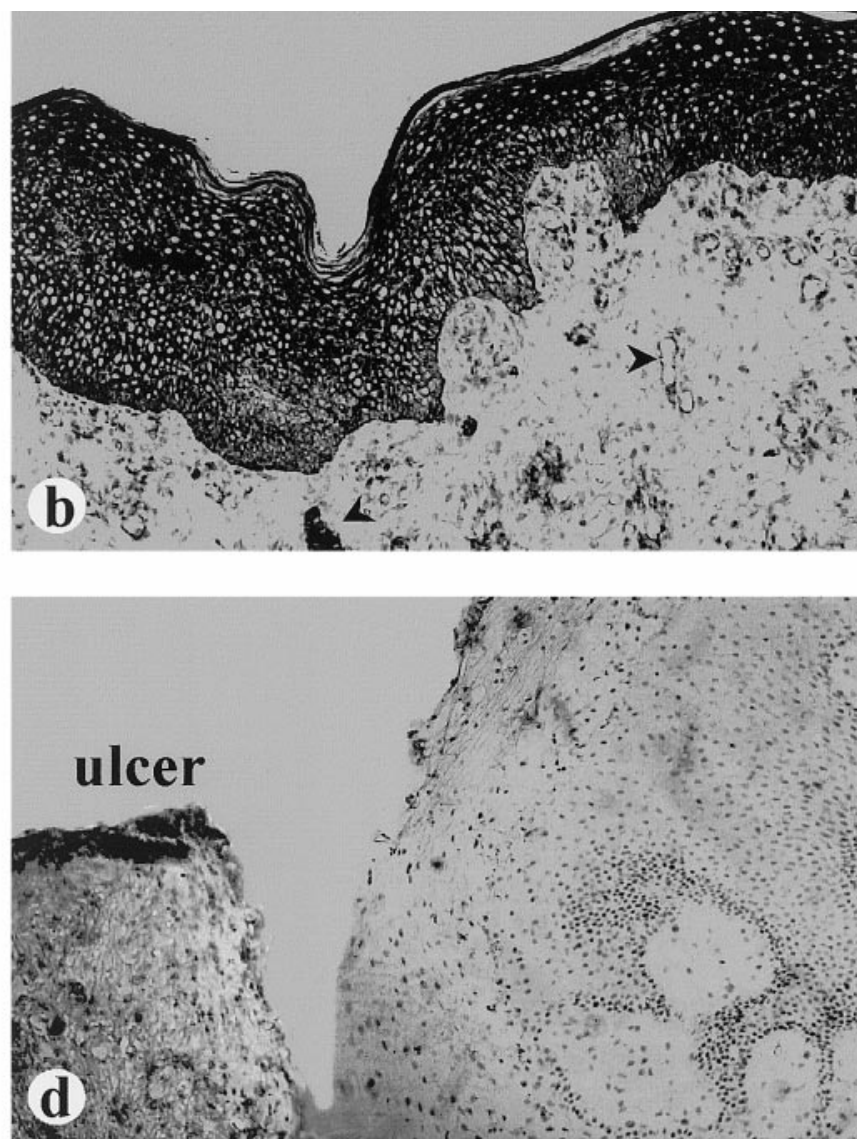

lysaccharide treated J774.2 macrophages as an internal control (data not shown). The profile of $i$ NOS protein were similar to that for $e c$ NOS with the greatest levels occurring in DFU patients.

Western blot analysis of arginase. Arginase protein was detected as a discrete band at $70 \mathrm{kDa}$. DFU patients contained elevated levels of arginase in comparison to normal skin, with barely detectable levels in diabetic skin (see Fig. 6c).

Western blot analysis of TGF- $\beta 1$. As a band at $12 \mathrm{kDa}$ TGF- $\beta 1$ protein was detected. In normal and diabetic skin TGF- $\beta 1$ was present to a greater extent than in DFU (Fig. 6d).

\section{Discussion}

Nitric oxide and other free radicals such as superoxide and peroxynitrite have been implicated in the tissue destruction associated with a number of pathologies. For example, in immune complex-induced pulmonary fibrosis, the tissue destruction has been shown to be mediated by NO [20]. Diabetic foot ulcers are characterised by a mass of inflammatory cells adjacent to areas of necrosis [21]. In this study we have shown that at the site of ulceration, DFU patients have raised NOS activity compared with nor- 

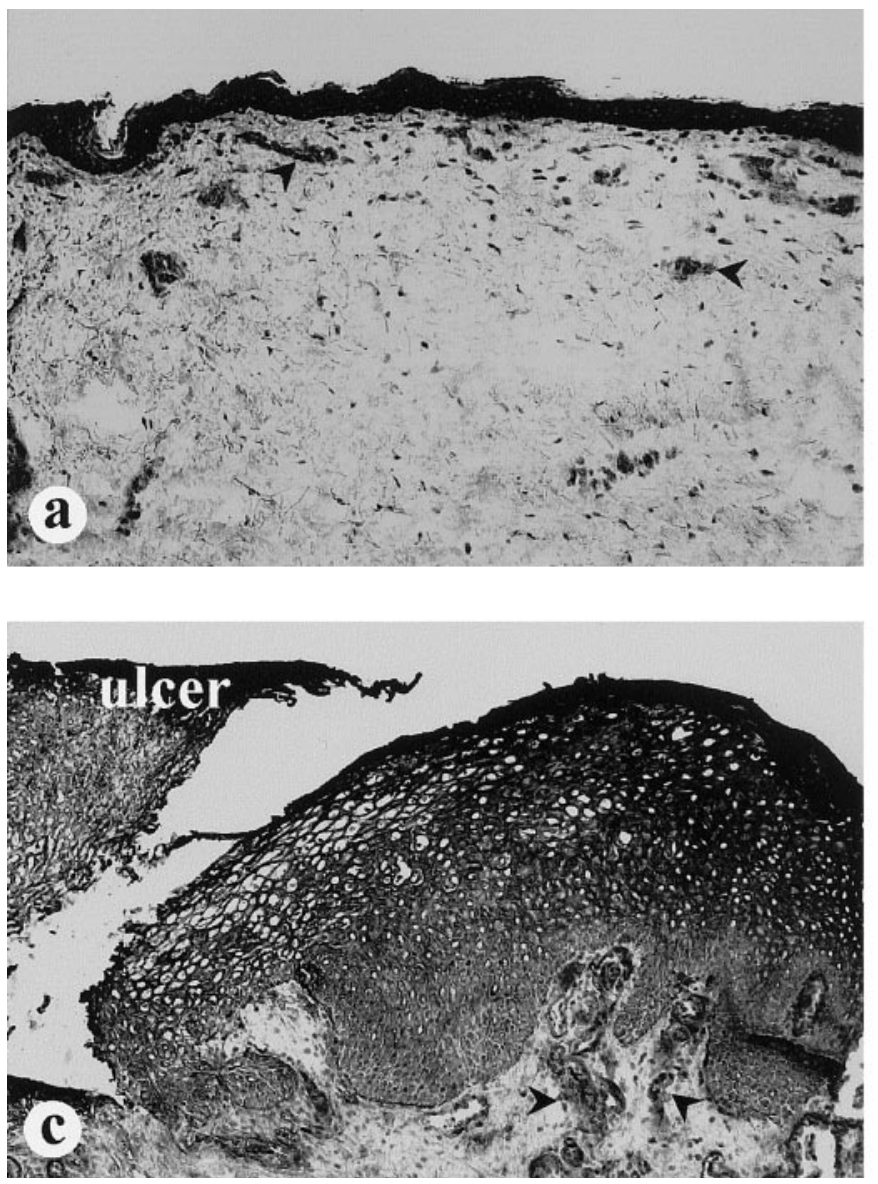

Fig.3a-d The distribution of immunoreactivity to $i$ NOS in a) normal skin; b) diabetic skin and c) DFU biopsies is shown. In d, primary antisera was replaced with normal serum as a negative control, in a serial section of $\mathbf{c}$. In $\mathbf{a}$ and $\mathbf{b}, i$ NOS was localised to a small proportion of blood vessels in the dermis (arrowed) and the smooth muscle of the erector pili muscle (star). In c, intense immunoreactivity to $i$ NOS in the vascular smooth muscle of a number of blood vessels is illustrated (arrowed). Inflammatory cells throughout the ulcer and at the margins of the dermis were also immunolabelled for $i$ NOS. Magnification $\times 65$

mal and diabetic skin. This was almost entirely if not exclusively attributable to the inducible isoform of NOS $i$ NOS. This was confirmed by western blot analysis. The results of the immunohistochemistry showed that the macrophage and other inflammatory cells in the central region of the ulcer were the source of this activity. In addition, this raised local activity of NOS was mirrored by increased plasma nitrite concentrations in DFU patients. These results therefore show the involvement of NO in the pathogenesis of DFUs. This was not merely due to the presence of local inflammation in the DFU group, as we have recently shown that DFU patients with recurrent ulcers have increased nitrite concentrations compared with diabetic non-ulcer patients and patients with non-re-
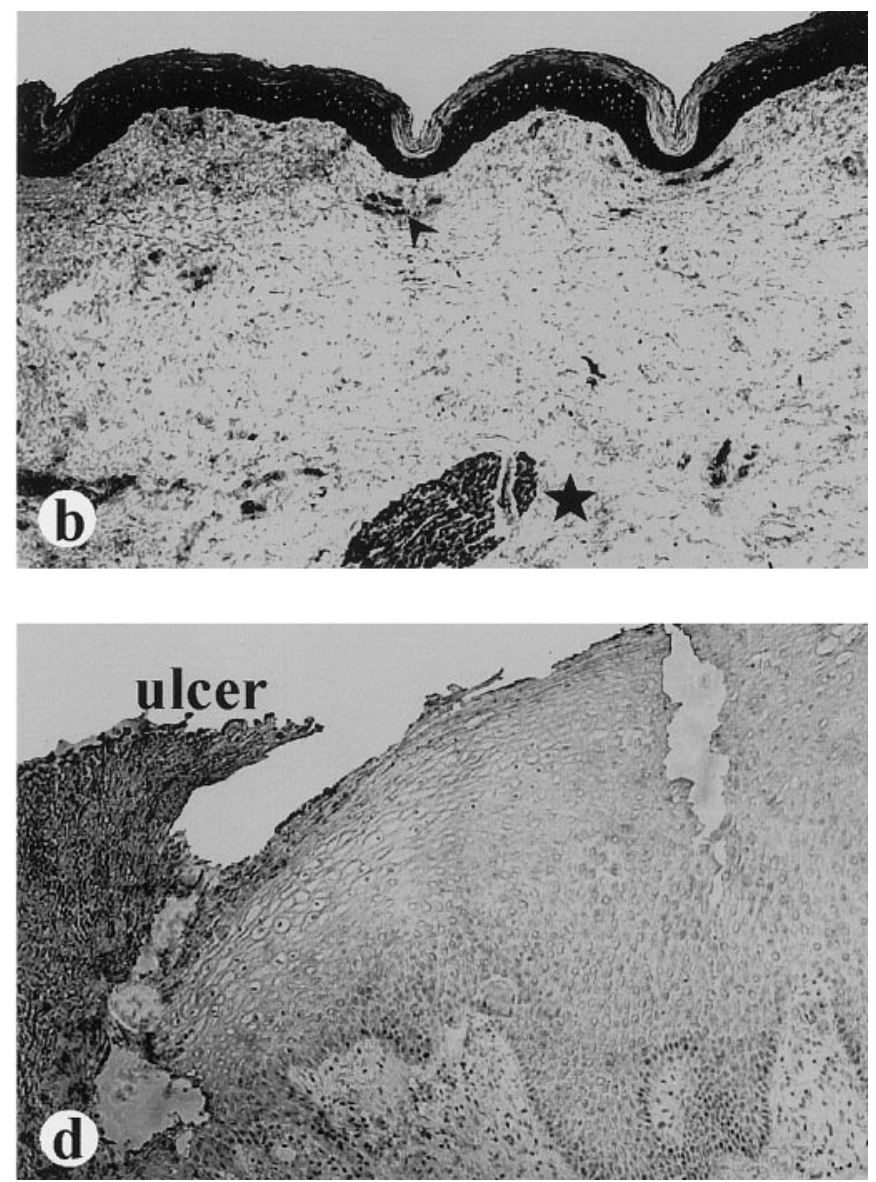

current ulcers [22]. In addition, we have shown that diabetic patients receiving insulin treatment had lower plasma nitrite concentrations than those receiving oral hypoglycaemic agents. It has recently been shown that the $i$ NOS pathway is upregulated in diabetes-prone rats and mice and in animals with diabetes induced by streptozotocin [23]. Furthermore, one study [23] showed that insulin treatment in all these groups reduced $i$ NOS activity. This therefore confirms our findings as all patients were receiving treatment and $i$ NOS was responsible for the elaboration of NO. It would, however, be difficult to obtain samples to determine NOS activity in non-treated diabetic patients.

It has recently been shown that ecNOS immunoreactivity in the skin of diabetic neuropathic patients and diabetic patients with neuropathy and vascular disease are reduced compared with control subjects [24]. It was suggested that this could be a contributing factor to the endothelial cell dysfunction observed in diabetic patients. We have confirmed the finding that diabetic patients have lower ecNOS than control subjects, however, in another study [24], the activity of ecNOS at the site of ulceration was not determined. We have therefore extended these observations by showing raised $e c \mathrm{NOS}$ and $i \mathrm{NOS}$ in DFU patients.

We have also shown increased arginase activity in DFUs compared with diabetic and normal skin. This 

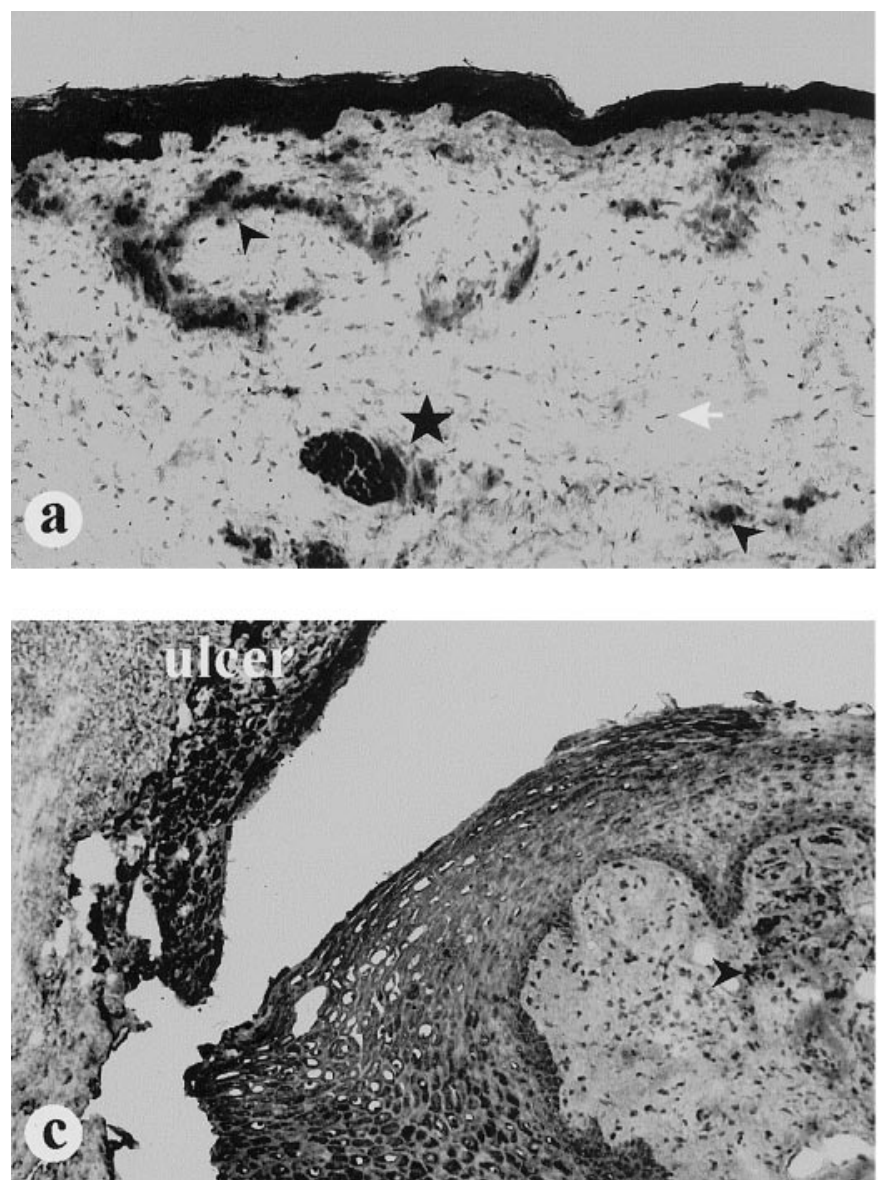

Fig.4a-d. a The immunolocalization of arginase in normal skin is shown. Intense labelling of blood vessels in the dermis was seen (arrows); smooth muscle (star) and fibroblasts were also immunolabelled. b Arginase immunoreactivity in diabetic skin is shown. Little if any labelling of any cellular elements was observed, although a small proportion of blood vessels were labelled. c The distribution of arginase in DFUs is shown. Note intense immunolabelling of the interface between the ulcer and the dermis. This is illustrated at higher magnification in d. Numerous blood vessels showed reactivity for arginase. The fibroblast (arrow, white) was, however, the major cellular source of arginase immunoreactivity, decreasing the more distal to the dermis. Magnification $\mathbf{a}, \mathbf{b}, \mathbf{c} \times 65 ; \mathbf{d}, \times 130$

could potentially result in excess matrix deposition. A characteristic of DFUs is the presence of callus. The raised arginase activity with resultant matrix deposition may thus be a contributing factor to callus formation and impaired wound healing. In addition, the pro-matrix forming effects of arginase may be counteracted by the tissue destructive effects of the raised concentrations of NO-derived from $i$ NOS. Unfortunately we were unable to substantiate this hypothesis by taking biopsies from a non-ulcerated site in the DFU group as it would be unethical to do so.

In this study the exclusion criteria for DFU patient selection was the presence of any clinical evidence of
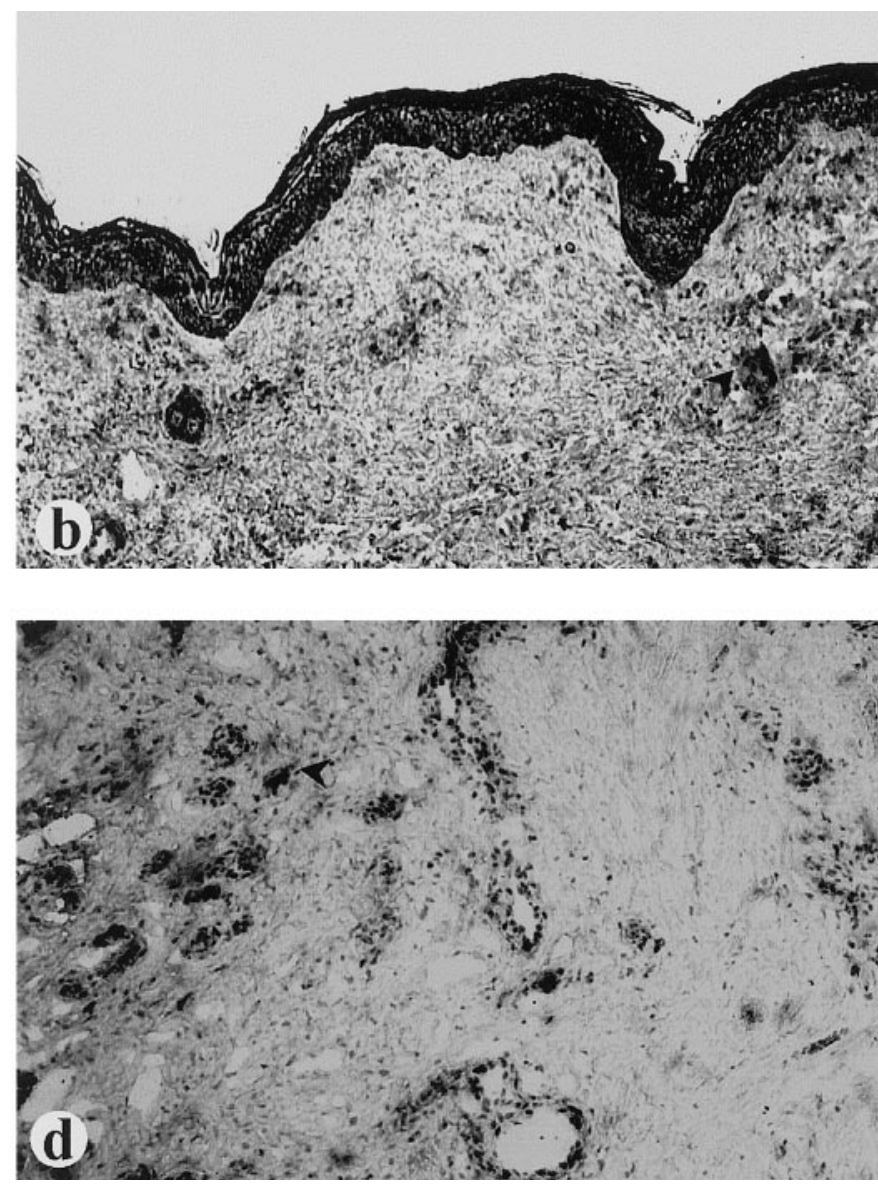

infection. In the polyvinyl alcohol sponge implant, a sterile model of wound repair, the major L-arginine derivative is L-citrulline up to day 3 , however, post day 3 ornithine and urea are the major products [25]. This may indicate a switch from the NOS to the arginase pathway. In contrast, we have previously shown that in a murine model of chronic granulomatous inflammation the persistence of microbial contamination and/or antigen results in raised and sustained NOS activity [26]. There are numerous factors which may regulate which pathway of L-arginine metabolism is operative. These include the persistence of microbial contamination, availability of L-arginine and the local cytokine environment. In the absence of microbial contamination it would be expected that NOS activity would decline and that arginase would predominate. One factor which may account for this is the local cytokine milieu with TGF- $\beta$ being a prime candidate. Transforming growth factor beta inhibits NOS activity but stimulates arginase [27]. This confirms and extends earlier observations that in acute thermal ulcers TGF- $\beta$ s 1,2 and 3 are expressed, whereas in chronic pressure ulcers only TGF- $\beta 3$ is expressed with no detection of TGF- $\beta 1$ and TGF- $\beta 2$. In addition, we were unable to show TGF- $\beta 1$ immunoreactivity in macrophages within the ulcer. This confirms previous findings that macrophages isolated from diabetic mice produced less TGF- $\beta 1$ than mac- 

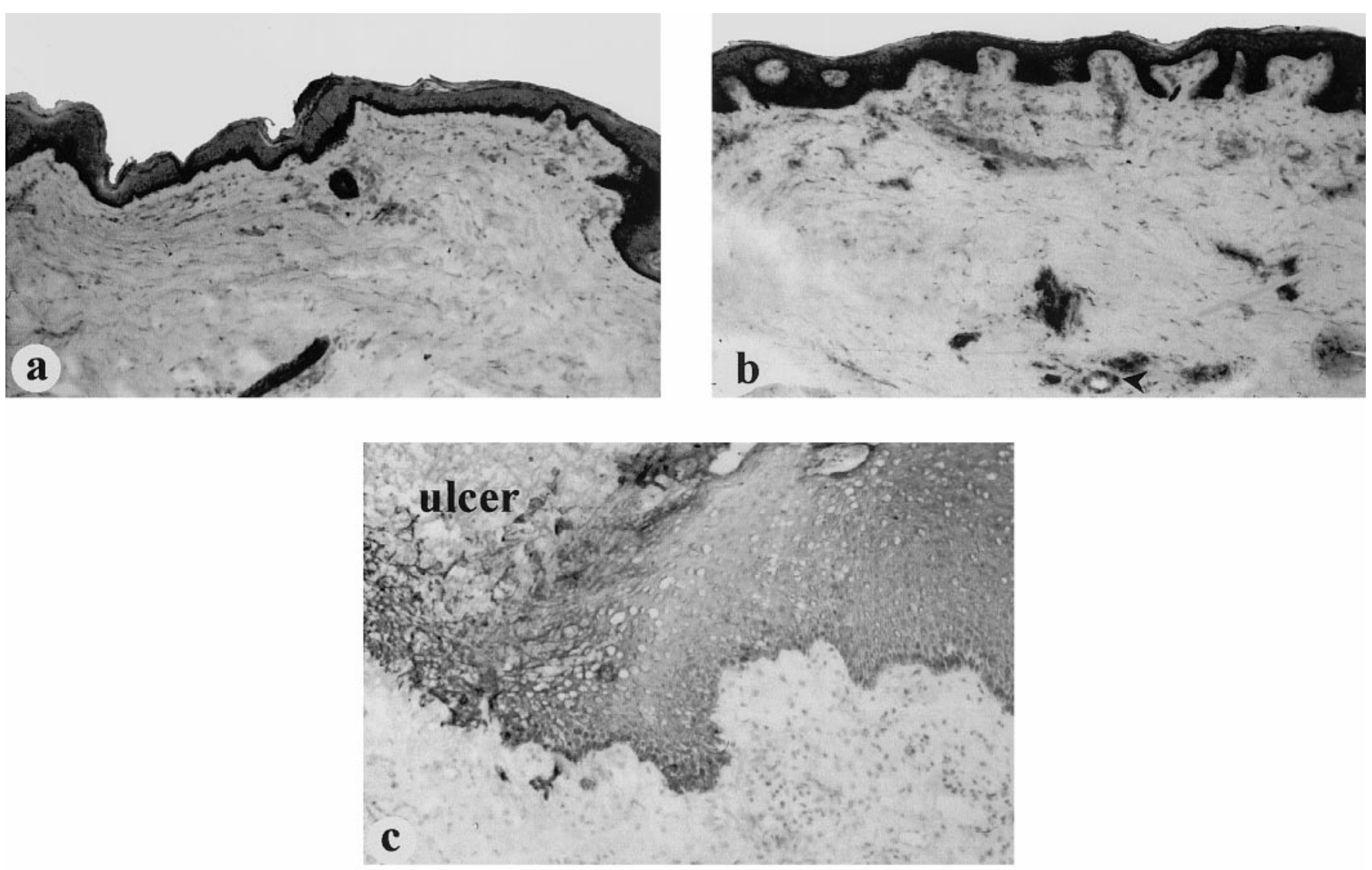

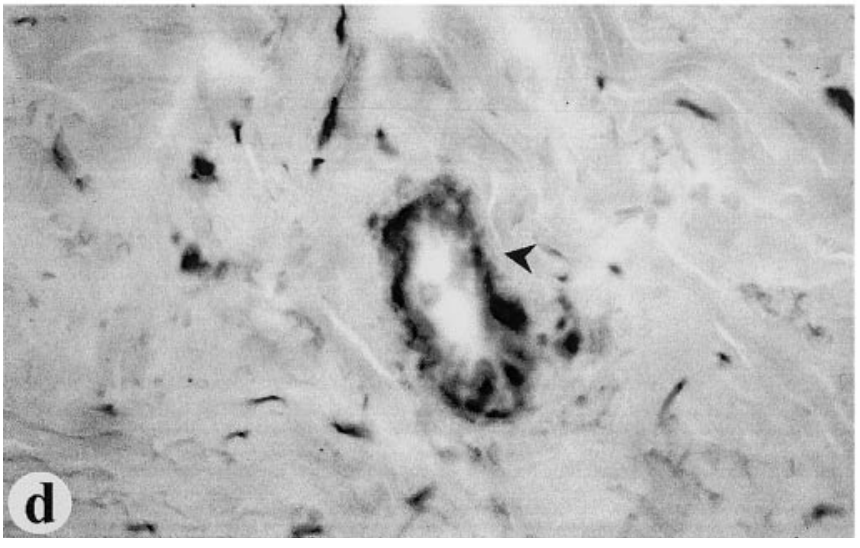

Fig. 5a-e Immunolocalization profile of TGF- $\beta 1$ in normal skin a, diabetic skin $\mathbf{b}$ and DFU c. In diabetic skin intense immunoreactivity was seen in all layers of the epidermis (being strongest in the basal layer) and dermis. In normal skin the profile was essentially as for diabetic skin but the intensity was considerably greater, as illustrated in a. Blood vessels (arrow) positively labelled for TGF- $\beta 1$ were also seen in the dermis d. In DFUs virtually no immunoreactivity to TGF- $\beta 1$ was observed, although a proportion of cells restricted to the basal layer of the epidermis adjacent to the ulcer showed some immunoreactivity as shown in c. Blood vessels and macrophages in the dermis and ulcer respectively were negatively labelled for TGF- $\beta 1$, as illustrated in e. Magnification $\mathbf{a}, \mathbf{b}$, $\mathbf{c}$ and $\mathbf{e} \times 33 ; \mathbf{d} \times 130$

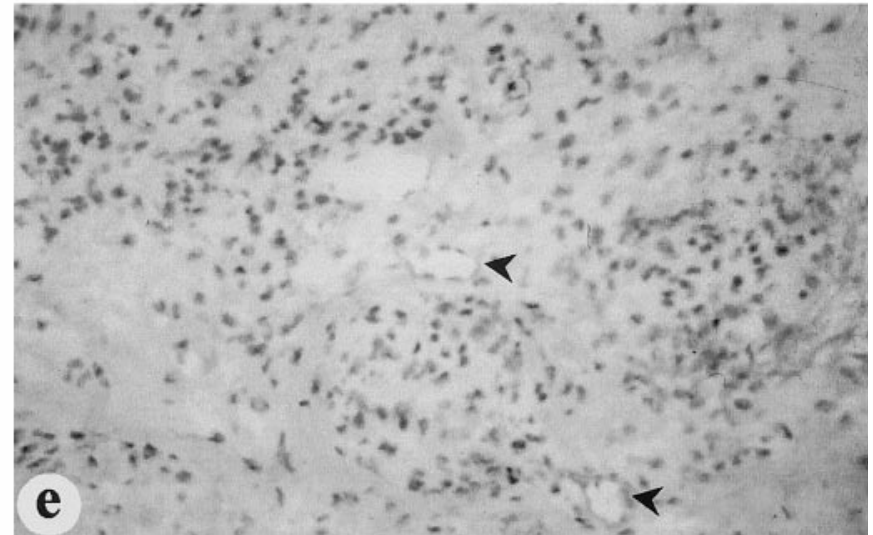

rophages from normal hosts [23]. Thus the reduced concentrations of TGF- $\beta 1$ in DFU patients may account for the raised and sustained activity of NOS as the normal homeostatic cytokine control mechanism is impaired.

In macrophages both the NOS and arginase pathway are in operation. Products of these pathways may affect the activity of their respective enzymes. For example, in macrophages, high concentrations of NOS-derived NO feedback to switch off NOS activity [29]. The ornithine product spermine, can inhibit NOS activity [30] and nitrite, the stable metabolite of NO, can suppress arginase activity [31]. Therefore the activity of these two enzyme systems, under normal conditions, would be mutually exclusive. We 
$\mathbf{a}$

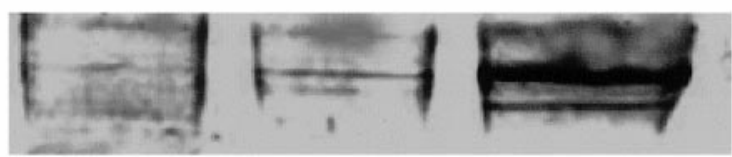

b

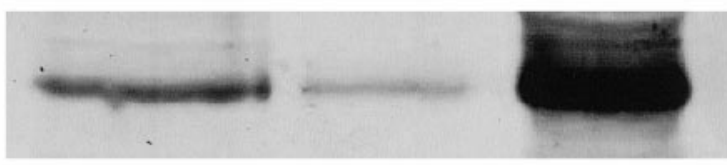

c

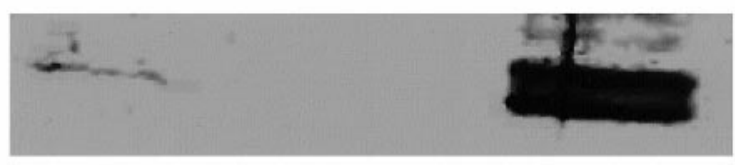

d

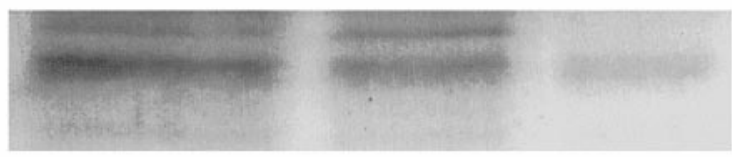

NS

DS

DFU

Fig. 6a-d Western blot analysis of $e c \operatorname{NOS} \mathbf{a}, i$ NOS $\mathbf{b}$, arginase c and TGF- $\beta 1$ d in normal skin, diabetic skin and DFU biopsies is illustrated. ecNOS protein and $i$ NOS protein occurred at a band of approximately $140 \mathrm{kDa}$. Both $e c \mathrm{NOS}$ and $i \mathrm{NOS}$, the highest levels of protein were observed in DFU samples with lower in normal and still lower in diabetic skin samples. Arginase protein was seen at a band of approximately $70 \mathrm{kDa}$. High levels of arginase protein were shown in DFU samples compared with normal skin but arginase was barely detectable in diabetic skin. TGF- $\beta 1$ protein was detected at $12 \mathrm{kDa}$. Lower concentrations of TGF- $\beta 1$ were observed in DFU compared with normal and diabetic skin.

have shown increased activity of both NOS and arginase in DFUs. The spatial distribution of these two enzymes was, however, distinct and was therefore not expressed in the same cells. For example, $i$ NOS was localised to the central area of the ulcer with the macrophage being the major cell type, whereas arginase was predominately localised to the ulcer edge and base with the fibroblast as the major source. The ecNOS profile was similar to that of arginase, being localised to endothelial cells of the vasculature at the margins of the ulcer. This suggests that each enzyme has a different role. It is well established that NO-derived from $i$ NOS is produced in large quantities, whereas $\mathrm{NO}$ from the constitutive isoform, ec NOS, is produced in much lower quantities. A role for $\mathrm{NO}$ in angiogenesis has previously been implicated. The evidence indicates that $\mathrm{NO}$ is an important regulator of angiogenesis under basal conditions and an inhibitor of agents which promote the angiogenic response $[32,33]$. On the basis of our observations we suggest that $i$ NOS at the centre of the ulcer is acting to remove microbial contamination as a means to debride the wound. The persistence of high $i$ NOS activity could, however, be deleterious to the normal healing process. This is similar to previous findings that implicated NO as possibly being deleterious to wound healing in a model of sepsis [34]. Selective suppression of $i$ NOS activity might therefore be beneficial. This could, however, result in promotion of infection as NO is crucial to host defence. The combined use of antibiotics with a NOS inhibitor might address this problem. Endothelial nitric oxide synthase may participate in the angiogenic response and arginase is implicated in callus formation, although other factors play a part in the latter such as neuropathy and increased foot pressures.

Acknowledgements. Dr. E. B. Jude was supported by a grant from the British Diabetic Association. I. Appleton is funded by a Royal Society Research Fellowship.

\section{References}

1. Bild DE, Selby JV, Sinnock P, Browner WS, Braveman P, Showstack JA (1989) Lower-extremity amputation in people with diabetes. Epidemiology and prevention. Diabetes Care 12: 24-31

2. Williams DRR (1985) Hospital admissions of diabetic patients: information from hospital activity analysis. Diabet Med 2: 27-32

3. Boulton AJM (1997) Foot problems in patients with diabetes mellitus. In: Pickup JC, Williams G (eds) Textbook of diabetes. Blackwell Science 2nd edn., pp 58; 1-58

4. Thomson FJ, Veves A, Ashe H et al. (1991) A team approach to diabetic foot care - the Manchester experience. The Foot 2: 75-82

5. Appleton I, Tomlinson A, Willoughby DA (1996) Induction of cyclo-oxygenase and nitric oxide synthase in inflammation. Adv Pharmacol 35: 27-78

6. Kolls J, Xie J, LeBlanc R et al. (1994) Rapid induction of messenger RNA for nitric oxide synthase II in rat neutrophils in vivo by endotoxin and its suppression by prednisolone. Proc Soc Exp Biol Med 205: 220-225

7. Granger DL, Hibbs JB Jr, Perfect JR, Durack DT (1988) Specific amino acid (L-arginine) requirement for the microbiostatic activity of murine macrophages. J Clin Invest 81 : 1129-1133

8. Drapier J-C, Hibbs JB Jr (1988) Differentiation of murine macrophages to express non-specific cytotoxicity for tumour cells results in L-arginine-dependent inhibition of mitochondrial iron-sulfur enzymes in the macrophage effector cells. J Immunol 140: 2829-2838

9. Hibbs JB, Taintor RR, Vavrin Z, Rachlin EM (1988) Nitric oxide: a cytotoxic activated macrophage effector molecule. Biochem Biophys Res Commun 157: 87-94

10. Stuehr DJ, Nathan CF (1989) Nitric oxide. A macrophage product responsible for cytostasis and respiratory inhibition in tumour target cells. J Exp Med 169: 1543-1555

11. Hibbs JB Jr, Vavrin Z, Taintor RR (1987) L-arginine is required for expression of the activated macrophage effector mechanism causing selective metabolic inhibition in target cells. J Immunol 138: 550-565

12. Culcasi M, Lafon-Cazal M, Pietri S, Bockaert J (1994) Glutamate receptors induce a burst of superoxide via activation of nitric oxide synthase in arginine-depleted neurons. J Biol Chem 269: 12589-12593 
13. Pou S, Pou WS, Bredt DS, Snyder SH, Rosen GM (1992) Generation of superoxide by purified brain nitric oxide synthase. J Biol Chem 267: 24173-24176

14. Gartner ME, Shearer JD, Bereiter DF, Mills CD, Caldwell MD (1991) Wound fluid amino acid concentrations regulate the effect of epidermal growth factor on fibroblast replication. Surgery 110: 448-456

15. Radi R, Beckman JS, Bush KM, Freeman BA (1991) Peroxynitrite oxidation of sulfhydryls: the cytotoxic potential of superoxide and nitric oxide. J Biol Chem 266: 4244-4250

16. Beckman JS, Beckman TW, Chen J, Marshall PA, Freeman BA (1990) Apparent hydroxyl radical production by peroxynitrite: implications for endothelial injury from nitric oxide and superoxide. Proc Natl Acad Sci USA 87: 1620-1624

17. Selmeci L, Brosnan ME, Seiler N (1985) Recent progress in polyamine research. Akademiai Kiado, Budapest

18. Bradford MM (1976) A rapid and sensitive method for the quantitation of microgram quantities of protein utilising the principle of protein-dye binding. Anal Biochem 72: 248-254

19. Corraliza IM, Campo ML, Soler G, Modolell M (1994) Determination of arginiase activity in macrophages: a micromethod. J Immunol Methods 174: 231-235

20. Mulligan MS, Warren JS, Smith CW et al. (1992) Lung injury after deposition of $\operatorname{IgA}$ immune complexes. Requirements for CD18 and L-arginine. J Immunol 148: 3086-3092

21. Ferguson MWJ, Herrick SE, Spencer MJ, Shaw JE, Boulton AJM, Sloan P (1996) The histology of diabetic foot ulcers. Diabet Med 13: S30-S33

22. Tentolouris N, Jude EB, Ferguson MWJ, Appleton I, Boulton AJM (1998) Increased plasma nitric oxide in the aetiopathogenesis of recurrent neuropathic foot ulceration in diabetic patients. Diabet Med [Suppl 2]: 105

23. Stevens BR, Sutherland DER, Ansite JD et al. (1997) Insulin down regulates the inducible nitric oxide synthase pathway: nitric oxide as cause and effect of diabetes? J Immunol 159: 5329-5335

24. Veves A, Akbari CM, Primavera J et al. (1998) Endothelial dysfunction and the expression of endothelial nitric oxide synthetase in diabetic neuropathy, vascular disease, and foot ulceration. Diabetes 47: 457-463

25. Albina JE, Mills CD, Henry WL, Caldwell MD (1990) Temporal expression of different pathways of L-arginine metabolism in healing wounds. J Immunol 144: 3877-3880

26. Vane JR, Mitchell JA, Appleton I et al. (1994) Inducible isoforms of cyclooxygenase and nitric oxide synthase in inflammation. Proc Natl Acad Sci USA 91: 2046-2050

27. Boutard V, Havouis R, Fouqueray B, Philippe C, Moulinoux JP, Baud L (1995) Transforming growth factor beta stimulates arginase activity in macrophages. Implications for the regulation of macrophage cytotoxicity. J Immunol 155: 2077-2084

28. Schmidt P, Cox D, McMasteer G et al. (1993) TGF- $\beta$ s and TGF- $\beta$ Type II receptor in human epidermis: differential expression in acute and chronic skin wounds. J Pathol 171: 191-197

29. Griscavage JM, Rogers NE, Sherman MP, Ignarro LG (1993) Inducible nitric oxide synthase from a rat alveolar cell line is inhibited by nitric oxide. $\mathbf{J}$ Immunol 151: 6329-6337

30. Szabo C, Southan GJ, Wood E, Thiemermann C, Vane JR (1994) Inhibition by spermine of the induction of nitric oxide synthase in J774.2 macrophages: requirement of a serum factor. Br J Pharmacol 112: 355-356

31. Hrabak A, Bajor T, Temesi A, Meszaros G (1996) The inhibitory effect of nitrite a stable product of nitric oxide (NO) formation, on arginase. FEBS Lett 390: 203-206

32. Ausprunk DH, Knighton DR, Folkman J (1994) Differentiation of vascular endothelium in the chick chorioallantois: a structural and autoradiographic study. Dev Biol 38: 237-248

33. Pipili-Synetos E, Sakkoula E, Haralabopoulos G, Andriopoulou P, Persteris P, Maragoudakis ME (1994) Evidence that nitric oxide is an endogenous antiangiogenic mediator. Br J Pharmacol 111: 894-902

34. Thornton FJ, Ahrendt GM, Schaffer MR, Tantry US, Barbul A (1997) Sepsis impairs anastomotic collagen gene expression and synthesis: a possible role for nitric oxide. J Surg Res 69: 81-86 